\title{
Correlation between Hyperglycemia Stress and Short-Term Memory Function in Thrombotic Stroke Patients
}

\author{
Muhammad Hamdan ${ }^{1}$, Riani Wisnujono ${ }^{1}$, Yudha Haryono ${ }^{1}$, Abdulloh Machin ${ }^{1}$, Dian Puspitarini ${ }^{1}$ \\ ${ }^{1}$ Department of Neurology, Faculty of Medicine, Universitas Airlangga, Surabaya (60131), Indonesia
}

\begin{abstract}
Background: Hyperglycemic stress is associated with a disorder of the entire cognitive domain in the early phase of stroke, which is memory impairment. Acute changes in blood glucose are known to affect the cerebral blood flow.
\end{abstract}

Objectives: To determine the relationship between stress hyperglycemia with short-term memory function in thrombotic stroke patients.

Method: An observational analytic research with the case-control with a patient's of 72-hour onset thrombotic stroke that went to the Emergency Unit and was admitted to the Neurology Department of Dr. Soetomo General Hospital from January to December 2014. 42 subjects were enrolled (21 subjects in the case group and 21 subjects in the control group). The sampling of the study was conducted according to the cases that came in succession until the achievement of the subject was determined.

Results: After bivariate and multivariate analysis, hyperglycemic stress had no significant correlation to memory function $(\mathrm{p}=0.525)$ and OR $0.667(\mathrm{CI} 95 \%=0.190-2.334)$. There was a significant correlation between educational level and cognitive function $(p=0.003)$ also between hypertension and cognitive function $(\mathrm{p}=0.019)$.

Conclusion: Stress Hyperglycaemia has no significant relationship with memory function. Education levels and hypertension have a significant correlation with memory function.

Keywords: Memory Function, Word List Memory Task, Hyperglycemic Stress

\section{Introduction}

A stroke is an acute-onset neurological deficit syndrome, which persists for more than 24 hours. A stroke involves the focal central nervous system and is the result of cerebral circulatory disorders ${ }^{1}$. In acute ischemic stroke, there is a sudden decrease or the loss of blood that flow to the brain resulting in a neurological deficit. Most of the causes are atherothrombosis of the intracranial artery or large artery in the neck, as well as the

\section{Corresponding author:}

Riani Wisnujono

Department of Neurology, Faculty of Medicine, Universitas Airlangga, Surabaya (60131), Indonesia E-mail \& phone: wisnujonor@gmail.com, (+6231) 5020251 embolism of the heart ${ }^{2}$. Atherosclerosis is a pathological description of the most frequent vascular obstruction that causes a thrombotic stroke. Atherosclerotic plaque exist makes the blood flow to the area will decrease, it could even stop altogether. When the decreased blood flow to the minimal needs of the brain is unfulfilled, it will arise clinical symptoms ${ }^{3}$.

Hyperglycemia is a common manifestation of critical illness and surgery. Hyperglycemia is caused by acute metabolic and hormonal changes that correlation with response to the stress and injury. Hyperglycemia is one of the important risk factors for stroke that found in $\pm 43 \%$ of stroke patients, either due to the hyperglycemia stress and diabetes mellitus $(25 \%)^{4}$.

Cognitive understanding is the process whereby all the sensory input (tactile, visual, auditory) will be altered, 
processed, stored, and then used for perfect interneuron correlation, thus the individual is able to sense the sensory input. The cognitive domains or modalities according to Hodges consist of three modalities, namely: attention/concentration, memory, intellectual function, social behavior and personality. Memory is an individual process for storing and retrieving information ${ }^{5}$.

Acute stroke causes cognitive impairment not only in the location of infarct tissue but also in areas adjacent to inadequately perfused lesions. Global cognitive impairment might include memory impairment, attention, executive function or visuoconstruction among other cognitive domains ${ }^{6}$. Hyperglycemia is associated with the increased mortality and poor functional outcomes of post-stroke and might be a predictor of cognitive function output. Acute changes in the blood glucose are known to affect regional cerebral blood flow and cause osmotic changes in brain neurons.

\section{Method}

An observational analytic research with the casecontrol design was used in this study along with a patients of 72-hour onset thrombotic stroke that went to the Emergency Unit and was admitted to the Neurology Department of Dr. Soetomo General Hospital since January to December 2014. The subjects of the study were all thrombotic stroke patients treated in Seruni A, Seruni B, and Seruni Room and fulfilled inclusion and exclusion criteria that taken with consecutive sampling ${ }^{7}$. The control group is a patient with normal Word List Memory Task results, while the case group is a patient with an abnormal Word List Memory Task. The inclusion of cases and controls were adult patients (24-60) years old, the first-stage of thrombotic stroke had random blood sugar levels at admission (day 1 3 onset of stroke), had world list memory tasks value $<21$, GCS 456 , and willing to participate. The exclusion of cases and controls were patients who have impaired renal function and deafness (hearing loss). The dropout criteria were patients who died during the study period or patients who withdrew during the study period ${ }^{8}$.

This study has obtained approval from Dr. Soetomo General Hospital Surabaya ethical committee. The data taken were identity, height, and weight. Then, it performed a Word List Memory Task test for memory function and venous blood sampling to check the blood glucose, HbAlc, and cholesterol levels ${ }^{9}$. Furthermore, examining the CT Head Scan to support the diagnosis of thrombotic stroke. Statistical analysis was performed using SPSS 16.0 program. Collected categorical data were analyzed using Chi-Square test while numerical data were analyzed by unpaired t-test ${ }^{10}$.

\section{Result}

\section{Demographic Characteristics}

The subjects were 42 people, consisting of 24 men $(57.1 \%)$ and 18 women $(42.9 \%)$. In the case group, the number of male subjects was 14 people $(66.7 \%)$, while in the control group 10 people $(47.6 \%)$. The female subjects in the case group were $7(33.3 \%)$, while the control group was 11 people $(52.4 \%)$. Gender has no significant correlation to cognitive function with $\mathrm{p}=$ 0.212 (Table 1). The mean age of the subjects in the case group was almost the same (50.05 \pm 6.924 years), compared to the control group (51.05 \pm 7.032 years) $(p=0.645)$, resulting no age difference was found to cognitive function (Table 1).

The education level in the case group consisted of 11 people $(52.4 \%)$ graduated from elementary school, while 2 people $(9.5 \%)$ in the control group. The level of Senior High School, Vocational High School, and College in the case group consisted of 10 people (47.6\%), while $19(90.5 \%)$ people in the control group. There was a significant correlation between educational level and cognitive function $(\mathrm{p}=0.003)$ (Table 1$)$.

\section{Clinical Data}

Subjects characteristics based on hypertension in the case group found that stage 1 hypertension were 10 people $(47.6 \%)$, while in the control group were 3 (14.3). Then, Hypertension stage 2 in the case group were 11 people $(52,4 \%)$, while in control group were $18(85,7 \%)$. There was a significant correlation between hypertension and cognitive function $(p=0.019)$. Based on the risk factor of dyslipidemia, in the case group found that 11 people $(52,4 \%)$ had dyslipidemia, while in control group were $10(47,6 \%)$. Normal lipids subjects in the case group were 10 people $(47.6 \%)$, while in the control group were 11 (52.4\%). There was no significant association between dyslipidemia and cognitive function $(p=0.758)($ Table 2$)$. In the case group, 7 people $(33 \%)$ had hyperglycemia stress and in the control group were $9(42.9 \%)$, while in the case group unstressed hyperglycemia were $14(66,7 \%)$, and in the control group were $12(57.1 \%)$. Stress hyperglycemia have no significant correlation to cognitive function $(p=0.525)$. 
(Table 2).

Correlation of Odds Ratio (OR) between stress hyperglycemia and cognitive function was 0.667 with Confidence Interval $(95 \% \mathrm{CI}=0.190-2.334)$, which means hyperglycemia stress to be 0.667 times more frequent for cognitive function impairment (protective factor), where it was obtained number 1 among Confidence Interval indicating that this relationship was not clinically significant (Table 3).

Table 1 Clinical Characteristics of Research Subjects

\begin{tabular}{|c|c|c|c|c|}
\hline \multirow[b]{2}{*}{ Subject Variable } & \multicolumn{2}{|l|}{ Group } & \multirow{2}{*}{$\begin{array}{l}\text { Total } \\
\mathrm{n}=\mathbf{4 2}\end{array}$} & \multirow[b]{2}{*}{$\mathbf{P}$} \\
\hline & $\begin{array}{l}\text { Case } \\
n=21\end{array}$ & $\begin{array}{l}\text { Control } \\
n=21\end{array}$ & & \\
\hline \multicolumn{5}{|l|}{$\begin{array}{l}\text { Hypertension } \\
\text { Stage } 1\end{array}$} \\
\hline Stage 2 & $10(47.6 \%)$ & $3(14.3 \%)$ & 13 & \\
\hline Dyslipidemia & $11(52.4 \%)$ & $18(85.7 \%)$ & 29 & 0.019 \\
\hline Yes & $11(52.4 \%)$ & $10(47.6 \%)$ & 21 & \\
\hline No & $10(47.6 \%)$ & $11(52.4 \%)$ & 21 & 0.758 \\
\hline Stress & & & & \\
\hline Hyperglycemia & $7(33.3 \%)$ & $9(42.9 \%)$ & 16 & 0.525 \\
\hline Yes & $14(66.7 \%)$ & $12(57.1 \%)$ & 26 & \\
\hline No & & & & \\
\hline
\end{tabular}

Table 2 Correlation between Hyperglycemia Stress with Cognitive Function

\begin{tabular}{|c|c|c|c|c|c|c|}
\hline & \multicolumn{4}{|c|}{ Cognition Function } & \multirow{3}{*}{ p } & \multirow{3}{*}{ RO (IK 95\%) } \\
\hline & \multicolumn{2}{|c|}{ Case } & \multicolumn{2}{|c|}{ Control } & & \\
\hline & $\mathbf{N}$ & $\%$ & $\mathbf{N}$ & $\%$ & & \\
\hline $\begin{array}{l}\text { Hyperglycemia Stress } \\
\text { Yes } \\
\text { No }\end{array}$ & \begin{tabular}{|l}
7 \\
14
\end{tabular} & $\begin{array}{l}33.3 \\
66.7\end{array}$ & $\begin{array}{l}9 \\
12\end{array}$ & $\begin{array}{l}42.9 \\
57.1\end{array}$ & 0.525 & $0.667(0.190-2.334)$ \\
\hline Total & \multicolumn{2}{|c|}{21100} & \multicolumn{2}{|c|}{21100} & & \\
\hline
\end{tabular}

\section{Discussion}

The sex ratio was 24 men $(57.1 \%)$ and 18 woman $(42.9 \%)$. This relevant to stroke epidemiologic data that men have more strokes experience than women. The mean age of the case group subjects was almost the same (50.05 \pm 6.924 years) compared to the control group $(51.05 \pm 7.032$ years). The mean age of the subjects was relatively young compared to the stated that the mean age was $65 \pm 11.6$ years. This study found a significant relationship between the level of education with cognitive function $(p=0.003)$. This was consistent with other studies suggest that education levels have an effect on memory.

A significant correlation was found between hypertension with cognitive function $(p=0.019)$. This is in accordance with research conducted by Tsao et,al that hypertension plays a role to decrease the cognitive function including memory. The changes in regional brain blood flow in hypertensive patients affect the cognitive function ${ }^{11}$. Hypertension causes a direct consequence of demyelination due to hypoxia and ischemia and might lead to subcortical-cortical disconnection. There was 
no significant correlation between dyslipidemia and cognitive function. This was consistent with studies suggest that there was no significant correlation between changes in plasma cholesterol levels and cognitive function ${ }^{12}$.

Based on hyperglycemia risk factors, in the case group, fewer patients had hyperglycemia stress than the control group, but no significant relationship was found between hyperglycemia stress and cognitive function $(p=0.525)$. This not in accordance with the study conducted by Pan, which states that hyperglycemia stress was associated with impairment in all cognitive domains including the memory in cortical infarction, but this not found in subcortical infarction ${ }^{13}$. This difference might due to this study that infarct stroke was not grouped based on its lesion location i.e., cortical and subcortical. Another cause was the age of the study subjects, in this study was $\leq 60$ years whereas in other studies was $<86$ years old ${ }^{14}$.

A study conducted by atkinson et,al states that $61 \%$ of patients that passed the acute period of stroke treatment and have a 1 or 0 NIHSS score encounter functional recovery well. But, the cognitive impairment was severe enough and only about $41 \%$ could return to work within 6 months after the stroke ${ }^{15}$. However, it was found that the location of lesions and lesion sides did not affect the occurrence of cognitive function impairment, while the size of the lesions had an effect on the occurrence of cognitive dysfunction. Patients with high NIHSS scores are more likely to experience psychomotor speed disorders. In studies conducted Danovska M, the type and severity of cognitive impairment depend on the stroke picture. The location and size of the lesions also affect the occurrence of cognitive impairment in stroke 16 .

\section{Conclusion}

There was no association between stress hyperglycemia with short-term memory function in patients with thrombotic stroke. Education levels and hypertension have a significant correlation with memory function. Further research using an observational analytic research method with a cohort design was needed, thus the results could be used to a better assessment of causal correlation.

Ethical Clearance: This research involves participants in the survey using sampling method that was accordant with the ethical research principle based on the regulation of research ethic committee. The present study was carried out in accordance with the research principles. This study implemented the basic principle ethics of respect, beneficence, nonmaleficence, and justice.

Conflict of Interest: The authors swear that there is no conflict of interest related with this paper.

Source of Funding: This study is done with authors' funding only.

\section{Author's Contribution}

Muhammad Hamdan, Yudha Haryono, Abdulloh Machin, and Dian Puspitarini are doing the laboratory research, while Riani Wisnujono is the initiator of the research as well as the one who writes the report of laboratory result into this paper.

\section{References}

1. Putri APS, Hidajah AC. Indicator of Dyslipidemia for Ischemic Stroke in Elderly with Hypertension. Indian J Public Heal Res Dev. 2019;10(3).

2. Hwang G, Kim JG, Song KS, Lee YJ, Villavicencio JB, Suroto NS, et al. Delayed ischemic stroke after stent-assisted coil placement in cerebral aneurysm: characteristics and optimal duration of preventative dual antiplatelet therapy. Radiology. 2014;273(1):194-201.

3. Santosa W, Kalanjati VP, Machin A. Are there any correlations between embolic stroke and previous post-traumatic epilepsy?-Study from a case report. In: IOP Conference Series: Materials Science and Engineering. IOP Publishing; 2018. p. 12326.

4. Bonaventura A, Vecchié A, Carbone S, Montecucco F, Abbate A. Comment on Hypoglycemia and hyperglycemia are risk factors for falls in the hospital population by Berra et al. Acta Diabetol. 2019;1-2.

5. Cappelletti S, Daria P, Sani G, Aromatario M. Caffeine: cognitive and physical performance enhancer or psychoactive drug? Curr Neuropharmacol. 2015;13(1):71-88.

6. Machin A, Hamdan M. Factors Associated with Onset to Hospital Delay among Stroke Patients in the Emergency Department. Indian J Public Heal Res Dev. 2018;9(11).

7. Kusumo AD, Bramantoro T, Berniyanti T, Wening GRS, Sosiawan A, Palupi R. Actuating food 
residual detection habit using self-made disclosing agent solution to improve the dental hygiene for fertile age mothers. J Int Oral Heal. 2019;11(1):33.

8. Kurniasari SF, Ulfiana E, Efendi F. The effect of sleep hygiene and brain gym on increasing elderly comfort and sleep quality. Indian J Public Heal Res Dev. 2018;9(12):589-94.

9. Thompson C, Henry JD, Rendell PG, Withall A, Brodaty H. Prospective memory function in mild cognitive impairment and early dementia. J Int Neuropsychol Soc. 2010;16(2):318-25.

10. Miftahussurur M, Yamaoka Y. Diagnostic methods of Helicobacter pylori infection for epidemiological studies: critical importance of indirect test validation. Biomed Res Int. 2016;2016.

11. Tsao T-M, Tsai M-J, Hwang J-S, Su T-C. Health effects of seasonal variation in cardiovascular hemodynamics among workers in forest environments. Hypertens Res. 2019;42(2):223.

12. Ponirakis G, Petropoulos IN, Alam U, Ferdousi M, Asghar O, Marshall A, et al. Hypertension
Contributes to Neuropathy in Patients with Type 1 Diabetes. Am J Hypertens. 2019;

13. Tziomalos K, Dimitriou P, Bouziana SD, Spanou M, Kostaki S, Angelopoulou S-M, et al. Stress hyperglycemia and acute ischemic stroke inhospital outcome. Metabolism. 2017;67:99-105.

14. Pan Y, Cai X, Jing J, Meng X, Li H, Wang Y, et al. Stress hyperglycemia and prognosis of minor ischemic stroke and transient ischemic attack: the CHANCE study (clopidogrel in high-risk patients with acute nondisabling cerebrovascular events). Stroke. 2017;48(11):3006-11.

15. Atkinson C, Whitley E, Ness A, BakerI. Associations between types of dietary fat and fish intake and risk of stroke in the Caerphilly Prospective Study (CaPS). Public Health. 2011;125(6):345-8.

16. Osei E, Den Hertog HM, Berkhemer OA, Fransen PSS, Roos Y, Beumer D, et al. Increased admission and fasting glucose are associated with unfavorable short-term outcome after intra-arterial treatment of ischemic stroke in the MR CLEAN pretrial cohort. J Neurol Sci. 2016;371:1-5. 